\title{
A Study on Bioadsorption of Synthetic Dye Using Guava (Psidium guajava) Leaves
}

\author{
Manasee Vichare (Author) \\ Dept. of biochemistry \\ Ramnarain Ruia Autonomous College \\ Mumbai, India- 400019
}

Abstract:-

$>$ Background:

Guava (Psidium guajava, white Indian) is common fruit bearing plant found throughout the Indian peninsula. It is said to be native to Mexico and Southern America and now can be found in many of the Asian countries. It is grown in tropical and sub-tropical region around the world. Guava leaves have shown many properties like antibacterial, bioadsorbent, etc. The bioadsorbent property can be exploited to remove coloured residues from water bodies. Problems like water pollution have arisen due to rapid industrialization and urbanization. Various harmful dyes like Coomassie brilliant blue, used in both textile industries and laboratories, are expelled into water bodies. To reduce the effects of such dye on ecology the research was carried out using guava leaves as bioadsorbent. That being the case the Coomassie brilliant blue solution at different $\mathrm{pH}$ was treated with guava leaf powder and the decrease in absorbance was noted at $625 \mathrm{~nm}$.

\section{$>$ Material and Methods:}

The Guava leaves were obtained from Mumbai suburban. The leaves were dried and powdered for further testing as bioadsorbent. All the chemicals have been used were of analytical grade.

\section{Result:}

The study showed high absorption rate in acidic medium as the colour changed from dark blue to light blue. The optimum pH for bio-adsorption was found to be 3. As the amount of guava leaf powder increased, the rate of adsorption also increased.

\section{Conclusion:}

Guava leaf powder is effective as a bioadsorption as rate of adsorption increases with increase in guava leaf powder. With further optimization it can become potential source of adsorbent.

Keywords:- Guava, Leaf Powder, Bioadsorption, Coomassie Brilliant Blue, Low Cost Bioadsorbent.

\author{
Prashant Masali (Author) \\ Dept. of biochemistry \\ Ramnarain Ruia Autonomous College \\ Mumbai, India- 400019
}

I. INTRODUCTION

Guava (Psidium guajava) is familiar fruit bearing plant found all over the Indian peninsula. The Spanish first observed the fruit in Mexico and from there it was taken to various parts of the world. There are different varieties of guava plant depending upon its flesh colour. The pulp also shows high concentration of beta-carotenes, lycopene, betacryptoxanthin and polyphenols which has given plant its anti-antioxidant properties along with vitamin $\mathrm{C}$ which is found 5 times more than the oranges ${ }^{[5]}$. The leaves of guava plant show presence of many volatile oils and other chemical compounds which gives them characteristic fragrance and other medicinal properties. The guava leaves extract shows many medicinal properties like antibacterial, antifungal, anti- inflammatory etc. ${ }^{[1]}$.

\section{METHODS AND MATERIALS}

The guava leaves sample was obtained from residential area in Ghatkopar east, Mumbai- 400 075. The leaves were fully matured, green in colour.

Study Design: Colorimetric assessment of subsiding dye colour

Study Location: The study was conducted in Ramnarain Ruia Autonomous College, Matunga, Mumbai, Maharashtra.

Study Duration: September 2019- December 2019

\section{> Procedure Methodology:}

The guava leaf powder was prepared by method given by Rabia Rehman ${ }^{[6]}$. Guava leaves were collected from home garden. The adsorbent was washed in order to remove dust particles and impurities and then air dried, followed by oven drying at $70^{\circ} \mathrm{C}$ for two hours. This is the sample of the untreated bio-adsorbent. Bio-adsorbent was chemically treated with acetone by dipping $100 \mathrm{~g}$ of dried powder into $400 \mathrm{~mL}$ of acetone solution for 24 hours. After filtration, it was again dried out in oven at $70^{\circ} \mathrm{C}$ for two hours. The bio-adsorption of synthetic dye was carried out by suspension method [7] [8]. The dye was prepared by mixing $1 \mathrm{~g}$ of Coomassie brilliant blue in citrate buffer, having concentration of $20 \mathrm{mg} / \mathrm{L}$. 


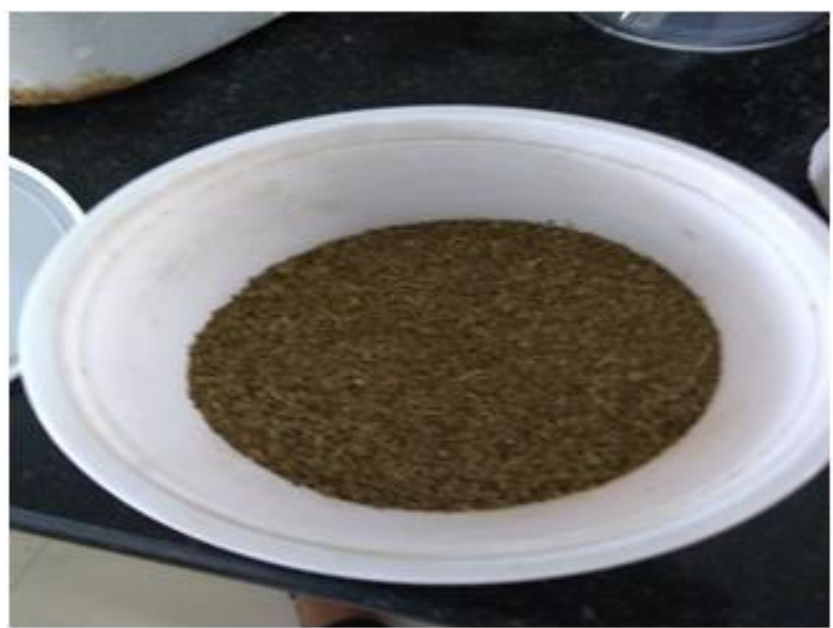

Fig 1:- Guava leaf powder

\section{RESULTS}

\section{Effect of $p H$}

In accordance with fig. 2, maximum adsorbance was seen at $\mathrm{pH} 3$. Heeding to the further study the optimum $\mathrm{pH}$ was found to be 3.2 , in the $\mathrm{pH}$ range $2.8-3.6$

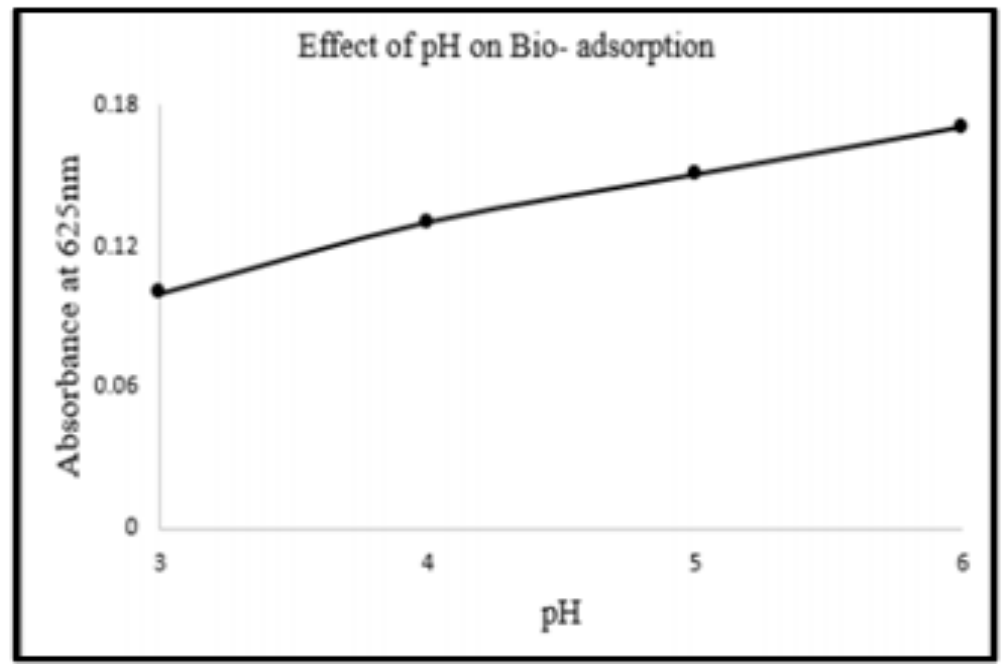

Fig 2:- Bioadsorption at different $\mathrm{pH}$ range (a)

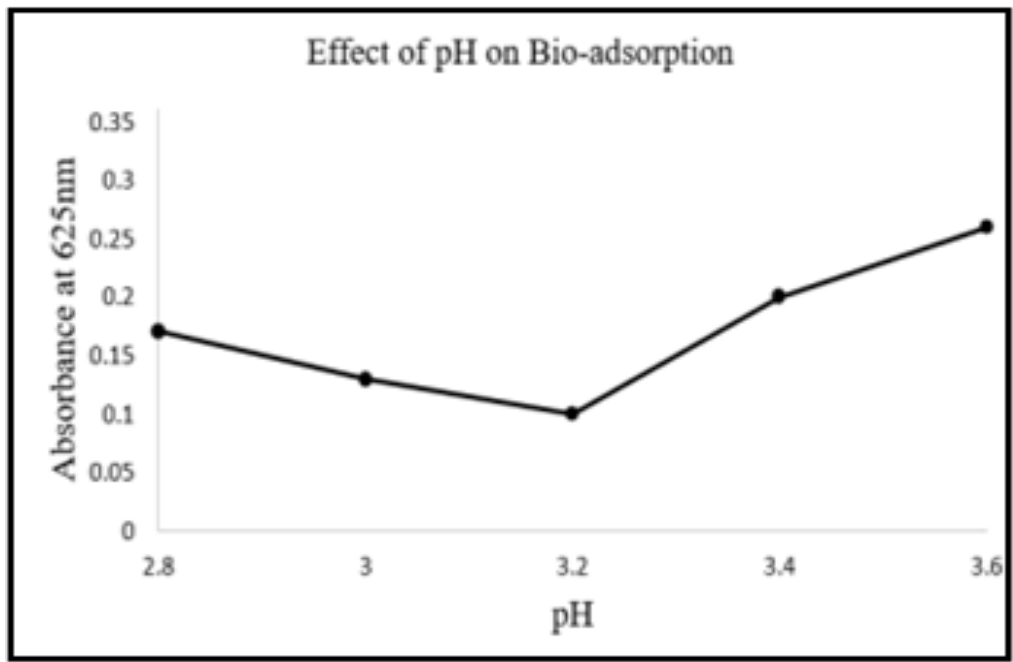

Fig 3:- Bioadsorption at different $\mathrm{pH}$ range (b) 


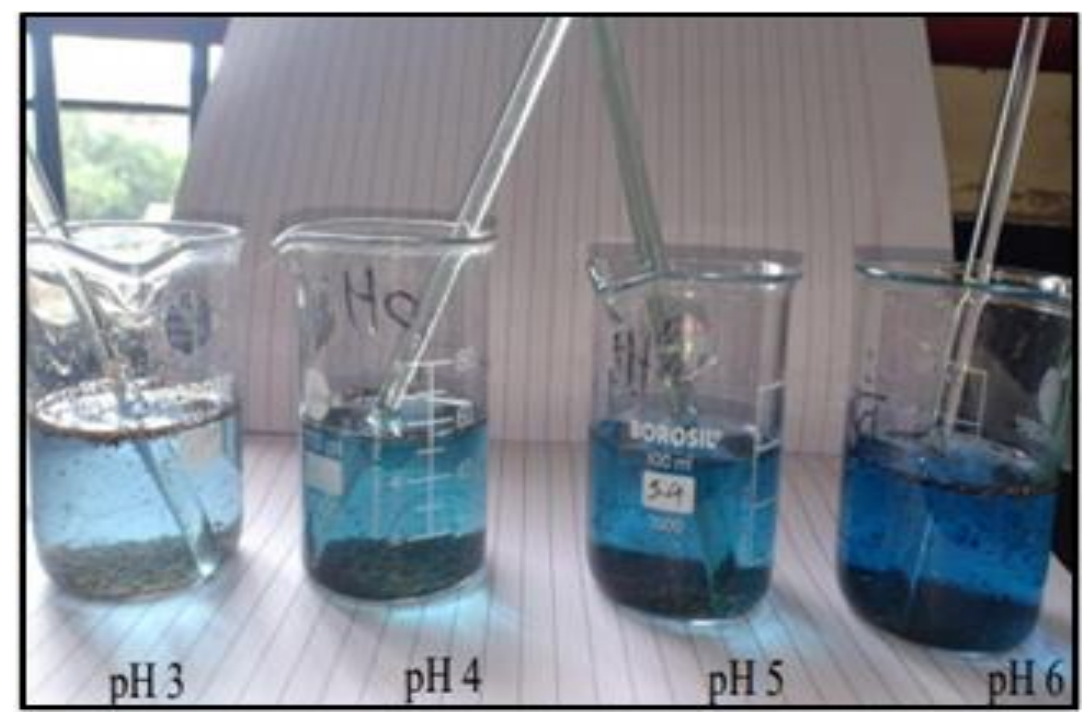

Fig 4:- Bioadsorption at different $\mathrm{pH}$ range (b)

Effect of addition of different amount of guava powder:

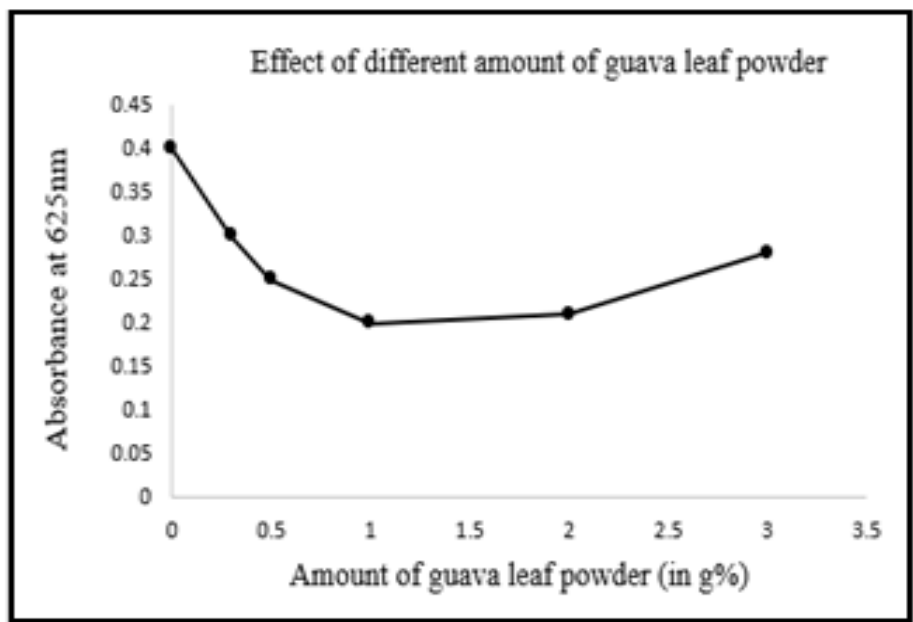

Fig 5:- Graphical representation of different amount of guava leaf powder

According to fig. 5, without addition of guava leaf powder the maximum absorbance of dye was found to be 0.40 After addition of guava leaf powder decrease in absorbance was noted. Upon addition of $1 \mathrm{~g} \%$ guava powder, absorbance decreased up to 0.2 .

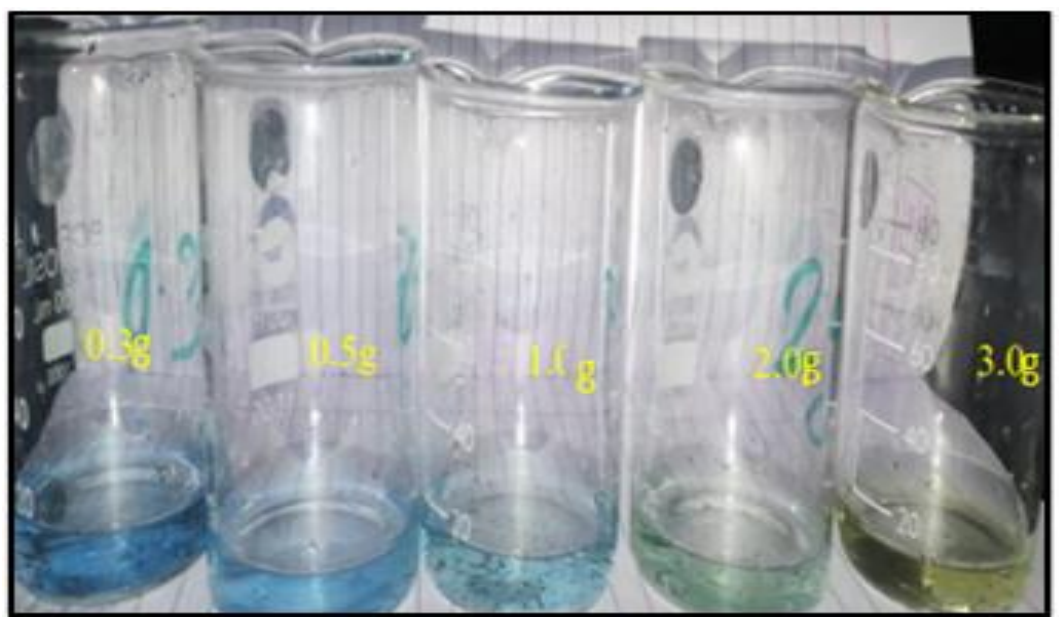

Fig 6:- Effect of addition of different amount of guava leaf powder on dye adsorption 


\section{DISSCUSSION}

The study was carried out on potential use of guava leaf powder as bio-adsorbent. The leaf powder was activated at $100^{\circ} \mathrm{C}-150^{\circ} \mathrm{C}$ for 2 hours. This temperature range was used to study adsorption efficiency of guava leaf powder. The increase in activation temperature, increased the adsorption capacity of guava leaf powder as the colour of solution changed from dark to light blue in short period of time. The $\mathrm{pH}$ of the solution also played an important role in the adsorption rate. The variation in $\mathrm{pH}$ range of dye was made by making dye in citrate buffer of range 3-6. The rate of adsorption decreased as the $\mathrm{pH}$ keep on increasing. The optimal $\mathrm{pH}$ was found to be 3 . With regards to difference in amount of leaf powder added, $0.5-1.5 \mathrm{~g} \%$ of powder can be added for better adsorption. After addition of $2 \mathrm{~g} \%$ or more powder the colour of solution changed from light blue to light green to olive green.

\section{CONCLUSION}

As guava showed increased rate of bioadsorption, guava leaves are effective bioadsorbent. Since addition of large quantity of guava powder produces green coloured solution, its amount must be optimized before inclusion. The maximum adsorption was observed at acidic $\mathrm{pH}$ making it suitable to treat acidic effluent. Owing to its good adsorption capacity, the bioadsorbent can be further investigated for its feasible use.

\section{REFERENCES}

[1]. Biswas B.; Rogers K.; McLaughlin F.; Daniels D.; Yadav A., (2013). Antimicrobial Activities of Leaf Extracts of Guava (Psidium guajava L.) on Two Gram-Negative and Gram-Positive Bacteria.

[2]. Débora Noma Okamoto; Carlos Roberto Ceron; Gustavo Orlando BonillaRodriguez; Jóse Manzato; Lilian C.G. de Oliviera, (2010). Coomassie Brilliant blue dye toxicity screen using Drosophila melanogaster.

[3]. Mohd. Rafatullah; Othman Sulaiman; Rokiah Hashim; Anees Ahmad, (2010). Adsorption of methylene blue on low-cost adsorbents.

[4]. P Thorsheim, (2006), Inventing Pollution: Coal, Smoke, and Culture in Britain since 1800.

[5]. Ramírez A; Delahaye EP, (2011). Composición química y compuestos bioactivos presentes en pulpas de piña, guayaba y guanábana. Interciencia.

[6]. Rehman Rabia; Tariq Mahmud; Maria Irum, (2015). Brilliant Green Dye Elimination from Water Using Psidium guajava Leaves and Solanum tuberosum Peels as Adsorbents in Environmentally Benign Way

[7]. Selvaraj Raja, (2012). Decolourisation of Synthetic Dye by Guava (Psidium guajava) leaf powder- a statistical approach. Journal of chemical and pharmaceutical research.
[8]. Srinivas Ch.; Ch.Nagamani; T.PremSagar; Rajsekhar M.,(2010). Studies on biosorption of Cadmium on Psidium guajava leaves powder using statistical experimental design. Journal of Pharmaceutical Sciences and Research. 